\title{
«Agón»y «Polémos» \\ Polemocentrismo analítico y prioridad práctica de la amistad en el pensamiento político de Julien Freund
}

\author{
«Agón» and «Polémos». \\ Analytical Polemocentrism and Practical Priority \\ of Friendship in J. Freund's Political Thought
}

\author{
JUAN C. VALDERRAMA ABENZA \\ Universidad CEU Cardenal Herrera (Valencia)
}

Recibido: 25/01/2016 Aceptado:10/03/2016

\section{RESUMEN}

Destacado representante de la tradición realista de lo político en la Europa de la segunda mitad del siglo XX, la obra de J. Freund ha sido entendida muy habitualmente como uno de los más acabados desarrollos teóricos del «conflictualismo político» schmittiano. La interpretación freundeana, sin embargo, está lejos de poder reducirse a esta única dimensión, articulada alrededor de la antítesis «amigo-enemigo». En este artículo se pretende ofrecer una revisión crítica de este tópico desde una lectura comprehensiva de la obra del autor francés, siguiendo como clave de lectura su intento de conciliación teórica entre el punto de vista del pensamiento político clásico y el moderno.

\section{PALABRAS CLAVE \\ REALISMO POLÍTICO, BIEN COMÚN, HOSTIS, POLÉMOS}

\footnotetext{
ABSTRACT

Well-known representative of political realism tradition in the Europe of the second half of $20^{\text {th }}$ century, J. Freund'work has currently been understood as one of the most accomplished

(C) Contrastes. Revista Internacional de Filosofía, vol. XXII-N ${ }^{\circ} 1$ (2017), pp. 119-136. ISSN: 1136-4076 Departamento de Filosofía, Universidad de Málaga, Facultad de Filosofía y Letras Campus de Teatinos, E-29071 Málaga (España)
} 
developments of schmittian «politics as conflict theory». Freund's interpretation cannot be reduced to this only dimension based on the analytical «friend-enemy» opposition. In this article we intend to offer a critical revision of this topic from a comprehensive reading of the work of French author, following as interpretative key his attempt to theoretical reconciliation between classical and modern political point of view.

KEY WORDS

POLITICAL REALISM, COMMON GOOD, HOSTIS, POLÉMOS

\section{De J. Hyppolite a R. Aron (y vuelta)}

ERAN LAS NAVIDADES DE 1958, en la céntrica Brasserie Balzar, a unos pocos pasos del Collège de France. Se trataba de una reunión urgente, a instancias de Jean Hyppolite. Junto a él, Julien Freund, su doctorando, y un antiguo profesor suyo en Estrasburgo, ahora en La Sorbona, Georges Canguilhem, quien no quiso perderse aquella cita, quién sabe si sintiéndose responsable de haber unido él el destino de aquellos hombres cuya ruptura estaba a punto de presenciar irremediablemente. En efecto, había sido él quien aconsejó a Freund tomar como director a Hyppolite, en lugar de Jankélévitch, ${ }^{1}$ como hubiera sido natural tratándose del único catedrático de filosofía política por aquel entonces en París. De todos modos Canguilhem poco podía hacer en esta nueva ocasión. Entre Hyppolite y Freund el desacuerdo era tal que resultaba prácticamente imposible restaurar la confianza mutua, ni siquiera con vistas a la defensa de aquel trabajo que iba avanzando lentamente bajo el ambicioso título todavía de Essence et signification de la politique. El problema no era menor, desde luego: era cuestión de principios. «Yo soy pacifista y socialista -le espetó Hyppolite-. No puedo dirigir en la Sorbona una tesis en la que se dice que 'no hay política más que ahí donde hay un enemigo'»... Freund se mostró inflexible: no, aquella no era una exageración retórica de la que pudiera desprenderse fácilmente, ni una idea tangencial en su proyecto de investigación. Al contrario; renunciar a esta u otras tantas letanías semejantes, suponía arrancar de cuajo el corazón mismo, no solo de su concepción de lo político, sino de algo todavía más profundo y que estaba en su base: su propia experiencia personal de antiguo resistente en guerra; algo respecto de lo cual aquella investigación había venido a ser como un largo proceso de depuración intelectual, como una fatigosa exorcización de los demonios conocidos. No le quedaba pues otra salida, como le advirtió Hyppolite: tenía que buscarse un nuevo director. ${ }^{2}$

1 J. Freund 1981, p. 28; J. Freund 1991, p. 42.

2 Cf. J. Freund 1973b; J. C. Valderrama 2006, pp. 34-44; J. C. Valderrama 2014, pp. 104-106, 109 ss. 
Esa misma tarde Freund escribió a Raymond Aron pidiéndole que dirigiera ese trabajo que acaba de rechazar su director. El porqué de esta elección es simple. En los momentos gestacionales de su tesis había acariciado ya esta posibilidad. Incluso buscó ocasión de conocerle en persona en su despacho de Calmann-Levy, adonde le visitó en 1952. Aron ejercía sobre él la impronta de un maestro desde hacía varios años, tras su lectura apasionada en plena guerra de La sociologie allemande contemporaine (1935), que simultaneaba con sus actividades en la Resistencia. Además, «se trataba de uno de los pocos intelectuales del momento que no concebía lo político según los oropeles de una ideología», ${ }^{3}$ y eso, en aquellos tiempos de sobrexcitación política, a Freund le interesaba muy especialmente.

No obstante, en aquellos primeros años de los 50, Aron no era todavía profesor en La Sorbona, sino en el Institut d'Études Politiques, por lo que no podía dirigir su investigación. Después, ya incardinado en la Universidad (1955), sí, como le hará saber al recibir su invitación en carta del 3 de enero de 1959. ${ }^{4}$ Desde entonces, y con la posterior incorporación de Freund al área de sociología del C.N.R.S., las relaciones entre ambos se fortalecerían muy notablemente.

En todo caso, Hyppolite seguiría muy de cerca el desarrollo de aquel estudio que tan destacado lugar habría de merecer entre los clásicos de la filosofía política de la segunda mitad del s. XX. Su presencia, querida por el propio Freund, en el acto de su defensa pública - «es bueno tener delante al enemigo», se decía ${ }^{5}-$, dio lugar a uno de esos momentos legendarios de la historia de la ciencia política europea que en la década de los 60 parecía obligar a los autores a tomar partido por formas completamente irreconciliables de afrontar las ultimidades del existir político.

Fue unos años después, el 26 de enero de 1965. La sala estaba rebosante. Bajo la mirada atenta de los otros miembros del tribunal -el propio Hyppolite, Paul Ricoeur y Pierre-Paul Sagave, de Nanterre-, Aron se felicitó por que un antiguo combatiente hubiera llevado a término semejante empresa. Luego intervino el doctorando, subrayando el vínculo de aquellas más de ochocientas páginas con su trayectoria previa en la militancia socialista y sindical. ${ }^{6} \mathrm{Fue}$ al término de su disertación cuando volvió Hyppolite sobre el valor del conflicto como factor lógicamente supuesto en la definición de lo político. «Si Ud. tiene razón, no me queda otra salida que ir a cuidar mi jardín», declaró. La respuesta de Freund fue inequívoca: «Como todos los pacifistas, Ud. cree que es quien

3 J. Freund 1985a, p. 55.

4 Cf. Ibid.; J. Freund 1991, pp. 43-44.

5 J. Freund 1980a, p. 33; J. Freund 1985a, p. 57.

6 Cf. J. Freund 1991, p. 44. 
elige a su enemigo. 'Como no queremos tener enemigos, no los tendremos', piensa. Sin embargo, es el enemigo quien le elige a Ud. Y si él quiere que Ud. sea su enemigo, lo será. Y le impedirá incluso cuidar su jardín». Otra vez una colisión irresoluble, sin respuesta posible: «En tal caso -concluyó Hyppolitesolo me queda el suicidio... ${ }^{7}$

No vale la pena buscar las posibles razones de semejante disyuntiva, entre el primado de la realidad o del deseo. Interesa detenerse ahora en otro aspecto, relativo a lo que algunos, tropezando en la misma piedra de escándalo, han considerado una hermenéutica polemocéntrica de lo político que sin embargo, como intentará mostrarse, no se compadece con la perspectiva epistemológica ni con el desarrollo temático de la teoría de Freund sobre el fenómeno.

II. ¿UNA VISIÓN POLEMOCÉNTRICA DE LO POLÍTICO?

\section{II.1. LAS DOS DIMENSIONES-POLÉMICA Y AGONAL-DE LA POLÍTICA}

Quizá sea este uno de los enfoques más corrientes en el creciente número de fuentes dedicadas a la teoría política freundeana. Entre sus avales, Norberto Bobbio, Giovanni Sartori, Pierpaolo Portinaro hasta cierto punto, PierreAndré Taguieff... Y quienes arriban a ella desde el análisis previo de la teoría jurídico-política de Schmitt, con quien le unían profundos lazos de amistad e intelectuales. De hecho, las raíces de esta lectura suelen hallarse en una polémica contraschmittiana anterior, de la que para algunos la teoría de Freund no representaría más que una explicitación en clave filosófica, víctima de la misma unilateralidad epistemológica supuesta en la articulación conceptual de lo político en torno a la dialéctica de amigo y enemigo.

A juicio de Sartori, ciertamente esta antítesis ilumina una de las modalidades decisivas de la existencia política - «politica come conflitto»o «come-guerra $\rangle^{8}$-, pero no su quidditas o esencia, que siempre se le escapa, como campo específico de acción más allá de las situaciones de excepción. Además, tiende a resolverse en beneficio del segundo término, entregando la política, aunque sea en un sentido exclusivamente lógico, a las relaciones conflictivas, y aún más específicamente, como su fórmula paradigmática, de guerra interestatal. ${ }^{9}$ De este modo es el enemigo (Feind), no el amigo (Freund), el que permitiría cualificar la acción política, por lo que sería vano buscar, fuese en Schmitt o en Freund, un tratamiento del primer extremo análogo al que obviamente sí ofrecen del segundo. Hay al contrario una asimetría implícita

7 Cf. Ibid., pp. 42-45; J. Freund 2004, p. VIII; J. Freund 1985a; J. C. Valderrama 2006, p. 69.

8 G. Sartori 1995, pp. 290, 291.

9 Cf. Ibid. p. 289; J.-V. Holeindre 2007, pp. 65-66; J.-V. Holeindre 2011, p. 60 ss. 
en la oposición que hace de la amistad reflujo simplemente de la hostilidad. ${ }^{10}$ Cierto, sigue Sartori, que el caso-límite permite explicar determinadas cosas; pero no todo, y desde luego, no lo más específico. Valdría solamente en casos de una política caliente - «calda»-, «intensa, combativa, apasionada, ideológica», pero no para la que con una misión más amplia tiene por objeto la pacificación de los conflictos por intermediación de la razón jurídica; ${ }^{11}$ la política como arte de enfriamiento y domesticación de la conflictividad: la «politica-come-pace», no «come-guerra» ya. ${ }^{12}$

En la misma dirección apunta Bobbio, para quien el emplazamiento del par amigo/enemigo en el centro gravitacional de la política, tiende a hacer de ella un asunto solo de potencia, reduciéndola casi en exclusiva a su dimensión securitaria. De modo que el saber político, como saber eminentemente práctico, termina sacrificado al puramente estratégico del uso de los medios, el cual, en cuanto tal, nada de fines sabe. Si la política se define por la intensidad que puede adoptar cualquier confrontación social; si como el propio Freund declara, «decir de algo que es político equivale a decir que es polémico» ${ }^{13}$, entonces, dice Bobbio, lo que permitirá entender ciertas formas sociales de oposición como formas de oposición políticas, residirá solo

En el hecho de que se trata de conflictos que no pueden ser resueltos en última instancia si no es a través de la fuerza, o que, por lo menos, justifican [...] el recurso a la fuerza para poner fin a la discusión. ${ }^{14}$

Aunque este es uno de los temas más recurrentes en las discusiones sobre la teoría jurídico-política schmittiana, no está claro que responda a la propia posición de Freund. Es cierto que en política, y especialmente en la política de Estado, «el motivo latente» ${ }^{15}$, dice Freund, de las confrontaciones y agitaciones sociales suelen concentrarse ahí, en torno al problema del acceso y mantenimiento del poder, el uso de la fuerza, la consolidación de los mecanismos jurídicos, simbólicos, retóricos de su legitimación social... Ahora bien, y es el propio Bobbio quien lo recuerda, aunque la fuerza pueda ser condición necesaria para el poder político, por sí sola no basta ${ }^{16}$. Fuerza puede encontrarse en prácticamente todos los grupos sociales; no así poder político, que apunta a una relación específica y más amplia.

10 Cf. Ibid., pp. 278, 286

11 Cf. G. Sartori 1995, p. 253.

12 Ibid. 1995, p. 292. Cf. P. Tommissen 1978, pp. 147-148.

13 J. Freund 2004, p. 446. Cf. C. Schmitt 2002, p. 68.

14 N. Bobbio 2005, p. 188.

15 J. Freund 1974a, p. 224.

$16 C f$. N. Bobbio 2005, p. 1218. 
En todo caso, de lo que en última instancia sospecha Bobbio, como antes Sartori, es de ese valor epistemológicamente determinante de lo polémico para el desciframiento de la estructura normal de lo político, el cual, por utilizar los términos específicos de Freund, tiende por esencia a fundar un orden regular de convivencia sobre una situación contraria, de carácter agonal. Es de ese cierto carácter polemocéntrico que, como advierte Portinaro, ${ }^{17}$ acaso obligue a los demás factores de lo político a orbitar alrededor del enemigo, pagando por ello el precio de verse absorbidos por él. ${ }^{18} \mathrm{~A}$ ello seguiría la postergación implícita de la dimensión agonal de la política, fundada en la domesticación racional de los conflictos, a esa otra dimensión polémica que late en el corazón de lo político, por la importancia que ahí reviste la dialéctica ami/ennemi. De modo que también Freund tendería a concentrar lo político en la esfera del hostis, como Schmitt, sin un tratamiento análogo, a todas luces necesario, del contenido de la amistad: ${ }^{19}$

Confinando el conflicto al ámbito de lo que llama état polémique, Freund termina sacrificando los logros de su distinción entre agonal y polémique, que se había revelado esencial para la investigación de la realidad política. Si la política no es tanto guerra y conflicto, cuanto capacidad también de transformar la lucha en duelo y éste en competición, operando una suerte de 'enfriamiento' del estado polémico en agonal, ¿no debería darse al lado de la polemología igualmente una 'agonología'? 20

\section{II.2. EL LUGAR DEL «POLÉMOS» EN LA POLÍTICA}

Es verdad que en el marco de sus investigaciones polemológicas Freund se centra preferentemente en el examen de las condiciones y formas del «état polémique», marcado por la oposición social entre partes en situación de «tertio excluso» («de la violence ouverte et directe ou celui du combat «réglé»" ${ }^{21}$; más desde luego que en las del «agonal», basada en fórmulas de compromiso y la institución de formas regulares de competencia entre adversarios («situation qui a réussi à désamorcer les conflits et à leur substituir une autre forme de rivalité connue sous le nom de compétition, de

17 Cf. P. Portinaro 1992, p. 300; J. Molina 2000b, p. 202 ss.

18 «Se da una parte infatti Freund tiene a sottolineare che la politica gode di 'uno statuto particolare nell'ambito della conflittualità', dall'altra egli finisce per appiattire la categoria del conflitto su quella distinzione amico-nemico che dovrebbe costituere proprio l'elemento di specificità della dimensione politica». P. Portinaro 1992, p. 299. Cf. J. Freund 1983, p. 361.

19 G. Sartori 1995, p. 286.

20 P. Portinaro 1992, pp. 299-300.

21 J. Freund 1983, p. 81. 
concurrence ou de concours» ${ }^{22}$ ). Así, por supuesto, en Sociologie du conflit (1983), donde Freund desarrolla esta distinción anunciada veinte años antes en L'essence du politique. ¿Pretendió con esto justificar el valor polémico que dice acompañar de forma natural -i.e., necesaria - a lo político? Sin duda; pero también -y esto conviene tenerlo en cuenta- la necesidad de su remisión práctica (pasando, pues, del terreno fenomenológico de lo político al práctico de la política) a condiciones racionales de normalidad, que son las que hacen de ella la forma máxima de civilización de los conflictos. Si analíticamente lo político incluye un cierto primado epistemológico del polémos y aún más, del hostis, lo que hace en cierto modo de L'essence du politique un campo particular de desarrollo de las ideas desgranadas en Sociologie du conflit, ${ }^{23}$ en la práctica, sin embargo, es el conflicto el que, en dirección inversa, se busca someter a la política, primando en consecuencia lo agonal.

Siendo forma «normal» de relación, en el sentido de no ser patológica, el conflicto debe intentar reconducirse a algún orden de acción -un ethosque pueda ceñirlo racionalmente y darle una medida práctica. Cuando la experiencia del conflicto recae sobre la existencia social en su conjunto, afectando a las condiciones mismas de su unidad, ese ethos se lo proporciona la política. Es entonces cuando la amistad toma la delantera a la enemistad y, socialmente, el agón al polémos, lo que desplaza el centro del problema político del terreno estratégico de los medios -especialmente enfatizados en la situación polémica- al de los fines. Y esto es lo decisivo. Porque desde el punto de vista de la finalidad de lo político, la amitié, por el estado agonal que presupone, no excluye la conflictividad ni su posible transformación en lucha. Dado que la paz no excluye al enemigo, sino que precisamente lo incluye al no poder hacerse más que con él -negarle vendría a ser de facto impedir la paz ${ }^{24}$ , cuanto se le pide a la política no es extirpar de raíz las condiciones de toda enemistad, sino en todo caso su civilización, tomando las medidas necesarias para que los conflictos sociales no degeneren en conflictos públicos, o para que si toman esta dimensión, al menos se les busque una solución satisfactoria. ${ }^{25}$ Es el que llama Freund, «el significado elemental [minimale] de la política»: ${ }^{26}$ darle políticamente forma agonal a la polemicidad social, latente o realmente encarnada en un conflicto.

En las últimas páginas de su Sociologie du conflit el propio Freund apuntaba -y así lo recordaba Portinaro- que «la política disfruta sociológicamente de un

22 Ibid. 1983, p. 83.

23 Cf. J. Molina 2000b, p. 202 y ss.; J. Giraldo 1999, p. 146.

$24 C f$. J. Freund 1963, p. 13 ss.; J. Freund 1987, p. 51; J. Freund 2004, p. 491.

25 Cf. J. Freund 1983, p. 362.

26 Ibid. 1983, p. 79. 
estatuto particular en el terreno conflictivo»; 27 pero esto es así básicamente, dice a renglón seguido, por la naturaleza de su fin. La política asume el factum conflictivo, no para convertirse en víctima de su lógica envolvente, sino para administrarlo de acuerdo con su propia estructura intencional, ya que es evidente que no es misión suya «atizar el fuego, sino preservar o restablecer el orden». ${ }^{28}$

El problema de nuestra vida política, por eso, va mucho más allá del orden público, como expresión concreta de la organización de los poderes del Estado al servicio de la protección y la defensa. Dando esto por supuesto, lo central reside en la posibilidad misma de participar socialmente en aquellos bienes por referencia a los cuales ese mismo orden se constituye. La condición política de tales bienes no deriva de la intensidad con que pudieran devenir objeto de conflicto entre voluntades antagónicas, en el sentido del Begriff de Schmitt, sino, más primariamente, de su adscripción a ese orden específico de acción que es el político.

\section{El DOBLE ÁNGULO DEL FIN DE LO POLÍTICO}

La conflictividad es un factor existencial que desborda en la práctica la sola relación de amigos y enemigos, abrazando también a los otros presupuestos que trazan, junto a él, el espacio de acción de la política, bien con relación a la constitución del orden público (mando-obediencia), bien a la organización en su interior (dominio de la opinión: público-privado). ${ }^{29}$ De este modo, la potencia polemógena del antagonismo no incide solamente sobre los tipos de relación adscritos a la dialéctica propia de la lucha y, por lo tanto, a la división existencial del mundo en amigos y enemigos. También el orden interior de la comunidad se ve afectado por esa vis polémica que lo político transmite a cuanto ciñe, incidiendo tanto en la articulación de lo privado y público como en las relaciones de gobierno. De ahí que no sea por eso exacto decir, como F. Chevrette hace años, tras su lectura de L'essence du Politique, que

La idea de presentar el par amigo-enemigo como presupuesto de la política exterior, sin abrir la política interior más que a la opinión, deja en cierto modo en penumbra todas las luchas políticas internas, personales, partidarias o ideológicas, ya que no está claro que la política interior esté menos impregnada por la lucha que por la opinión. ${ }^{30}$

27 J. Freund 1983, p. 361.

28 J. Freund 2004, p. 125.

29 Sobre la unidad orgánica de estos «presupuestos» que definen el espacio de la acción política (mando-obediencia, público-privado, amigo-enemigo), Ibid., p. 304, 338. Vid. J. C. Valderrama 2016.

30 F. Chevrette1969, p. 264 
Razones metodológicas condujeron a Freund a primar ahí la perspectiva exterior sobre la interior para el análisis de la enemistad, dejando en segundo plano -aunque sin ocultar- los aspectos relativos al antagonismo en el dominio de la opinión. Sin embargo, la naturaleza polemógena de la opinión también tuvo directa exploración en dicha obra. Cumple una función evidente en la determinación del sentido de la opinión pública, ${ }^{31}$ en la lucha por la representación, ${ }^{32}$ en la construcción de los instrumentos retóricos de legitimación de los fines del poder... ${ }^{33}$ Lo mismo sucede en lo relativo a la dialéctica de mando y obediencia, en la discriminación entre los órdenes privado y público, ${ }^{34} \mathrm{y}$ por supuesto en el derecho, aunque sobre la significación polemógena del derecho - entonces solo apuntada- Freund se detendría en otras fuentes.

De todos modos no es esta ahora la cuestión central. Importa sobre todo percatarse de que, en el horizonte de la situación polémica, lo político no revela su finalidad en lo que a todos sus aspectos se refiere. Solo indirectamente lo hace. Lo que situaciones así ponen de manifiesto es el riesgo que la propia conflictividad entraña para la continuidad en el tiempo de la unidad social, destacando así, como resulta obvio, el factor securitario sobre cualquier otro. Por eso, habida cuenta la siempre posible transformación en polémico de lo agonal, el fin de la política dirá Freund que consiste, restrictivamente, en la protección, esto es: «defender a unos de la violencia eventual de otros y asegurar, respecto al exterior, su seguridad contra toda amenaza externa». ${ }^{35} \mathrm{O}$ más simplificadamente: «la supervivencia, conservación y protección interior y exterior de una unidad política». ${ }^{36}$

Aunque este modo de determinar el objeto de la política -survie, protection, securité- es constante en los estudios políticos y polemológicos freundeanos, en realidad no constituye más que la «dimensión básica» o «mínima»-según explica él mismo- del bien común, en la cual la dialéctica amigo/enemigo cumple un papel determinante, ya que emplaza la política en el interior de una red de fuerzas antagónicas con las que es preciso contar para la organización del orden público. ${ }^{37}$

Desde luego, la posibilidad del enemigo es, en cuanto tal, estructural, dentro y fuera de la unidad social. Existencial y analíticamente política y conflictividad se presuponen; y aunque la reflexión sobre cada una ocupe

31 Cf. J. Freund 2004, pp. 371-382.

32 Cf. Ibid., pp. 382-412.

33 Cf. Ibid., pp. 142-151; 412-441; 684-688; 695-703.

34 Cf. Ibid., pp. 280-283; 291-304; 310-316.

35 J. Freund 1983, p. 361.

36 J. Freund 2004, p. 622.

37 Cf. Ibid., p. 653. 
estratos diferenciados de explicación, no es posible, en todo caso, absolver a lo político de su condición polémica ni, al revés, obviar del análisis polemológico una de sus dimensiones principales como ésa de su formalización por la política. Por eso no vacilará Freund al recordar con frecuencia que «il n'y a de politique que là où il y a un ennemi»,${ }^{38}$ que no existe la política sin enemigo posible, afirmación provocadora como pocas para la mirada éticamente pura de los partidarios de una paz abstracta y presuntamente neutra, sin enemistad. Muy al contrario, el enemigo es condición de la política. ${ }^{39}$ ¿Con quién, si no, podríamos hacer la paz? ${ }^{40}$ ¿O qué sentido podría tener una alianza? ¿Qué fin persiguen, de hecho, nuestras alianzas sino aumentar la potencia contra el enemigo posible, incluso cuando entre sus consignatarios puedan generarse a otra escala nuevas tensiones polemógenas $?^{41}$ La protección constituye uno de los objetivos fundamentales de la acción política, pero no agota su finalidad. Dimensión básica suya o mínima, su sentido le adviene de otra parte: de aquella forma de vida que representa el orden cuya protección de hecho se procura.

Y es que si puede hablarse de una dimensión mínima del bien común, será porque se pueda hablar también de alguna máxima. Así lo explicaba el propio Freund en «La peur de la peur» (1985): desde el punto de vista de sus fines, la política puede entenderse en función de un doble ángulo, el de lo máximo y lo mínimo. «En el primer caso - escribe-tiene por tarea, como enseñan Aristóteles o Tomás de Aquino, promover el bien común; en el segundo, según la doctrina de Hobbes, se limita a garantizar la protección». ${ }^{42} \mathrm{El}$ fin se presenta en el primero de acuerdo con las condiciones objetivas de un cierto ideal de vida (bonum vivere); en el segundo, en cambio, según las exigencias de la salus populi, como fórmula de contención de las amenazas intestinas o externas de desintegración. En este sentido, si para Aristóteles, como paradigma de la conciencia política clásica, la polis representa, en una óptica moralmente perfectiva, «la condición que permite al hombre responder a su vocación social y desarrollarse como individuo dentro de la colectividad», para Hobbes en cambio, y el pensamiento político arquetípicamente moderno, se retrotrae en lo fundamental a la «necesidad de templar los instintos agresivos o reprimir las actuaciones ilícitas y peligrosas de los humanos». ${ }^{43}$

Más explícito con el contenido de este segundo aspecto sería algo antes

38 Cf. Ibid., p. 448, 478, 491, 539.

39 Ibid., p. 446. «Supprimez l'ennemi -avisaba años antes- et vous supprimez du même coup la politique elle-même», J. Freund 1962, p. 62

40 Cf. J. Freund 2004, p. 655 ss.

41 Cf. Ibid., p. 481; J. Freund 1983, p. 291 ss.

42 J. Freund 1985b, p. 17.

43 J. Freund 2004, p. 752. 
en L'essence du politique, donde, continuando con su particular alianza entre Hobbes -de quien ahí parte analíticamente ${ }^{44}$ - y Aristóteles -en quien hallará las bases para el tratamiento de la concordia ${ }^{45}$-, perfilará algo más qué entiende por ese genérico «forger le bien commun» que rehabilita del pensamiento clásico: «el mantenimiento del orden -escribe- y el establecimiento de condiciones de vida razonables, lo que se corresponde con la paz interior en prosperidad de Hobbes». ${ }^{46}$ De manera que si la dimensión mínima del bien común apunta a la protección y la seguridad social, la máxima, por de pronto, a la prosperidad y al orden, concepto este que en la mente clásica se retrotrae al problema moral de la amistad, fundamento y contenido de la concordia. Esta philía presupuesta en la unidad social, y que le otorga sustancia y cohesión, es a la vez una comunidad de vida y de opinión, una «comunidad de sentido» ${ }^{47}$ en cuyos márgenes sus miembros se reconocen no solo como quienes no son enemigos, sino algo más: como compañía necesaria a un mismo fin. ${ }^{48}$ Esto es: amigos. Lo cual implica que los individuos concuerden en su interés por el bien de la colectividad, y que converjan, más allá de una pura lógica de pacto, en la forma de su orden como razón misma de su afecto. Tal cosa no exige, como el propio Aristóteles se cuidó de indicar en su momento, una unanimidad íntima en el juicio sobre el contenido de ese objeto, ya que no se trata de una simple igualdad en la opinión, que incluso entre extraños puede darse, ${ }^{49}$ sino una concordancia en el sentido de la acción común. Se trata del juicio práctico sobre el «bien» que representa para los sujetos mismos su unidad, como siendo en el dominio público -no necesariamente en los privados- una misma cosa en la continuidad del tiempo. Por esta concordancia trascienden los sujetos las exigencias de su simple coexistir, abriéndose al sentido moral de las relaciones que en esa unidad comparten según su forma históricamente concreta: «relations [...] d'un régime commun et parfois d'un système hiérarchique reconnu comme valable par l'ensemble». ${ }^{50}$ En efecto,

puesto que la concordia es amistad, presupone también una cierta identidad de sentimientos [...]. Ninguna colectividad puede permanecer unida $[\ldots]$ si sus miembros no comparten la necesidad de participar por así decirlo afectivamente en el conjunto social que ellos mismos constituyen..$^{51}$

44 Cf. Ibid., p. 653 ss.

45 Cf. Ibid., pp. 454-456; 658-660.

46 Ibid., p. 653.

47 J. Freund 2004, p. 462.

48 Cf. Ibid., p. 478.

$49 C f$. Aristóteles 1985, 1167a; Aristóteles 1989, 1261b 30-32; J. Freund 2004, p. 664.

50 J. Freund 2004, pp. 335-336.

51 Ibid., p. 661. Por eso «[i]l ne suffit pas non plus que la société soit organisée, structurée, 
Esta solidarité o unidad en el afecto, ${ }^{52}$ que se expresa en el devenir de las relaciones públicas, precisa junto a la afinidad en el juicio sobre el bien por ellas accesible, de criterios normativos para su realización, objetivadas en las reglas del derecho. No puede por eso extrañar que incluso abandonada la discusión sobre el significado del bien común en L'essence du politique, Freund introduzca en un momento dado la equidad entre los objetivos de la política, como condición formal de la concordia. ${ }^{53} \mathrm{Y}$ es que el orden al cual se orienta no basta con que sea simplemente un orden -que por sí mismo no pasa de ser una condición, no un fin-sino un orden lo mejor posible. ${ }^{54}$

Pero también Freund introdujo la «prosperidad» como parte integrante de la concordia pública. No el bienestar, por el que más bien se define lo económico, ${ }^{55}$ sino un elemento estructural del bien común que si es en su contenido asunto estrictamente económico, no en lo que toca a sus condiciones de posibilidad, cuya determinación atañe al obrar político, que así desvela el modelo social de su organización. De este modo se inscribe en el terreno que actualmente, consumado el triunfo de la estatalidad, delimita ese precipitado de la política de Estado que como dice Molina Cano es la política social, ${ }^{56} \mathrm{de}$ acuerdo con el régimen que permitiera darle forma a la organización colectiva en función de los problemas políticos planteados por el desarrollo de las actividades económicas, o a la inversa. En este sentido, la prosperidad no hace relación a los bienes cuantitativamente mensurables que permitieran el alcance del propio bienestar, sino, más bien, a la promoción pública de las condiciones sociales que a los individuos permitieran, mediante el desarrollo de sus actividades económicas, la libre satisfacción de sus necesidades. Lo políticamente relevante es eso: no la efectiva participación en un cierto género y número de bienes, sino la promoción social de las condiciones que hicieran posible su acceso, protegidas también por el derecho.

\section{EL HORIZONTE MORAL DEL BIEN COMÚN}

Con esta diferenciación de dimensiones bosqueja Freund su propia

hiérarchisée; il faut en plus que les membres qui y vivent aient le sentiment d'une unité qui est la raison de l'organisation», Ibid., p. 320.

$52 C f$. Ibid., p. 552.

53 Cf. Ibid., p. 732, 455; Aristóteles 1985, 159b 24-25.

54 Existe un estrecho vínculo entre orden y derecho que hace de éste regla en la organización de aquél, su representación y estructura normativa ( $\tau \alpha \dot{\xi} \xi 1 \varsigma)$ : $C f$. Aristóteles 1989, 1253a 36; J. Freund 2004, p. 717. De ahí el estatuto dialéctico del derecho, como mediación entre la capacidad estructurante de la potencia política y el propio ethos social como su límite y medida, Cf. C. Savès 1996, p. 83.

55 Cf. J. Freund 1993, p. 135.

$56 C f$. J. Molina 2007, p. 51; J. Molina 2004, p. 159 ss. 
articulación entre lo que a grandes líneas constituía el ideal moral del pensamiento ático y republicano latino, rehabilitados en el modelo civilizatorio cristiano meso y bajomedieval, y el imperativo estatal de la salus populi, que adoptará la forma de un orden próspero de paz en el sentido casi en exclusiva de seguro (Maquiavelo, Hobbes). ${ }^{57}$ Una articulación, en breve, entre la libertad y el orden: entre una concepción real de las libertades, en plural, públicas y también privadas, y las exigencias fundamentales del orden público. ${ }^{58}$ Sería un error no ver por eso en esta concepción más que lo afectado directamente por las condiciones de la situación excepcional-survie, conservation, protection-, condensándolo en el presupuesto amigo/enemigo. Si éste condiciona de modo prioritario la dimensión mínima del bien común, por apelar a la preservación de la unidad política y la vida personal, la máxima atañe sobre todo a los otros presupuestos, referidos a la constitución y organización del orden como particular forma de vida. No será por tanto simplemente lo necesario para la vida el objeto a proteger mediante la política, sino una determinada forma de entenderla, un ethos integrado en la totalidad de sentido de la vida humana, que el espacio público presupone sin haber creado y que se desarrolla fuera de los límites de la actividad política, dada siempre en relación con las demás «esencias». 59

Si el bien común no contuviera otra determinación que la que le ofrecen las exigencias de la protección, cualquier posible distinción de dimensiones estaría de más, y no tendría otro sentido la forma política de vida que el de favorecer las condiciones de la seguridad colectiva, lo cual es en el fondo solo, como había advertido Bobbio, asunto de potencia ${ }^{60}$ Cuando Freund apela a la dimensión máxima del bien común, apunta más allá, puesto que en última instancia «la finalidad específica de lo político se determina en función del sentido de una colectividad» ${ }^{61}$ y ésta, desde luego, no se agota en su potencia. Acaso resulte así un tanto unilateral no ver en la tarea de la política más que aquellos aspectos referidos a la protección del orden público, sin reparar en lo que de hecho hace de él mismo para la política un bien moral digno de especial defensa.

Parece que a Freund le es claro entonces, como a Aristóteles, que «los hombres no se han asociado simplemente para vivir, sino para vivir bien», ${ }^{62}$ y que esta formalización de su vivir, en su configuración máximamente comprensiva, es la que el propio orden de la comunidad ofrece como

$57 C f$. J. Freund 1980b, p. 30; J. Freund 2004, p. 653.

$58 C f$. J. Molina 2000a, p. 298.

59 J. Freund 2004, p. 658.

60 Ibid., p. 151.

61 Ibid., p. 650.

62 Aristóteles 1989, 1280a 31. 
posibilidad histórica a sus miembros. ${ }^{63} \mathrm{Si}$ vive el hombre en sociedad no es sino porque de alguna manera espera encontrar ahí mismo, en el cumplimiento del fin de la ciudad, una de las condiciones de la realización de su propio ser, uno de los elementos que estructuran su propia teleología natural como un ser que por naturaleza es socius, y solo socialmente puede darle forma a las posibilidades de su cumplimiento. ${ }^{64}$ En el contexto de esta realización, la seguridad no representa una condición externa, políticamente impropia, para el acceso a otros bienes que en cambio, por su especial carga moral, sí cumplirían propiamente el fin de la comunidad y, por su medio, del hombre. Al contrario, siendo uno de los aspectos estructurales del mismo bien, es por lo mismo uno de los objetivos que justifican la propia realidad social (política) del hombre.

\section{PRIORIDAD POLÍTICA DE LA AMISTAD}

A la luz de lo dicho, parece que si en el orden de la praxis el estado agonal, como se dijo, prima sobre el polémico, y lo mismo la amistad sobre la enemistad, entonces también la dimensión máxima del bien común -y así, entre otras cosas, el sentido de la libertad- está igualmente llamada a prevalecer sobre la mínima -resumidamente: el orden-. Esto significa que el equilibrio supuesto en el estado agonal de las relaciones sociales, se integra en el horizonte de la concordia pública como condición en la realización política de un bien que, sin embargo, lo trasciende. Lo agonal representa, en consecuencia, una condición estructural en la determinación política del bien común, del cual la seguridad forma parte en cuanto se ordena a la preservación de esa peculiar forma de vida. ${ }^{65}$ De modo que lo que veíamos que Portinaro antes le exigía a Freund -a saber: que el análisis de lo agonal no quedara preso de la «dynamique conflictuelle» de lo polémico- tiende a coincidir de hecho con lo que el propio Freund expone en el dominio de su filosofía política general, más que en el estrictamente polemológico. Que después esto permita decir que el polemocentrismo de la sociología del conflicto de Freund se integre en el horizonte de su politología en una suerte de agonocentrismo o, mejor, de «centralidad analítica de lo agonal», es otra cuestión. Todo dependerá de adónde se dirija la atención: si a las relaciones políticas de incidencia histórica, interestatales o civiles, o a las puramente analíticas de lo político con las demás «esencias», a la luz de su significación también antropológica.

63 Ibid., $1252 \mathrm{~b}$.

64 Cf. J. Freund 1983, p. 36.

65 Freund mismo se plantea en L'essence du politique la posible primacía de la concordia sobre la seguridad, sobre todo teniendo en cuenta la radicalidad del presupuesto amigo y enemigo: J. Freund 2004, pp. 449, 662-664. 
Freund, en todo caso, fue consciente apenas unos años antes de la defensa de su tesis de que si para el esclarecimiento de la política se le otorga la prioridad hermenéutica a la finalidad, el duplo schmittiano amigo/enemigo debía leerse primando la amistad sobre la enemistad. En este punto el lorenés no podía ser más explícito: «la finalidad política entendida como promoción del bien común - escribe- exige indudablemente que se le otorgue prioridad a la amistad», de manera que «el fin de lo político consiste en la paz interna y externa, aunque esta finalidad sea sin cesar objeto de discusiones, luchas y a menudo guerras, es decir, que se haga necesario superar en todas partes y siempre el obstáculo de la enemistad». ${ }^{66}$ Incluso nacida la excepción y con ella el enemigo, la disposición de los medios necesarios para su superación entraña formas también de relación amistosa, dadas en especial como alianza. La postergación analítica -desde lo político- de la amistad respecto de la enemistad en función del estado o situación excepcional no implica su subordinación a ella desde el punto de vista práctico, según las condiciones de realización de la política. La concentración del examen de lo político en los factores polémicos de tal situación se debe, fundamentalmente, tanto en el caso de Schmitt, primero, como en el de Freund después, a su valor revelador en términos epistemológicos y a su prioridad existencial por su radicalidad y urgencia. ${ }^{67}$

Su pronta conversión filosófica a un genérico aristotelismo le permitió marcar a Freund cierta distancia de ese posible polemocentrismo analítico schmittiano, tal y como él mismo quiso hacerle ver a Aron en carta de febrero de 1964, apenas un año antes de la obtención de su doctorado:

Si le damos la primacía a la enemistad, el problema de la finalidad de lo político deviene casi imposible de resolver, lo que no sucede si le damos la prioridad a la amistad. Usted [R.A.] me hizo amablemente reparar [...] en que mi tendencia era más schmittiana que aroniana. Así sería si yo le diera la preponderancia a la enemistad. ${ }^{68}$

Pero esto no sucede: vistas las cosas desde el fin, el enemigo no es primario. A quien se reconoce como tal es a quien no se puede llamar amigo, no al revés: no llamamos amigo al no-enemigo, sino enemigo, más bien, a quien no es amigo. ${ }^{69}$ Lo primero, en el dominio público, es la amistad.

66 Ibid., p. 664, 554.

67 Cf. M. Maffesoli 2005, p. 52.

68 Cf. P. Tommissen 2004, p. 120.

69 «Au regard de la finalité du politique, l'amitié semble donc avoir la priorité, de sorte que la notion d'inimitié ne reçoit sa pleine signification que parce qu'elle constitue l'obstacle à la réalisation souhaitée de la fin du politique», J. Freund 2004, p. 449. Cf. M. Maffesoli 1978, p. 102. 


\section{REFERENCIAS BIBLIOGRÁFICAS}

ARISTÓTELES 1985: Ética a Nicómaco, Madrid: C.E.C. , 1989: Política. Madrid: C.E.C.

BOBBIO, N. 2005: Teoría General de la Política. Madrid: Trotta.

CHEVRETTE, F. 1969: «A la recherche de l'essence du phénomène politique», Canadian Journal of Political Science (II:2): 262-264.

FREUND, J. 1962: «La passion de la politique», Foi et Vie (61:2): 42-64.

, 1963: «La paz 'inencontrable’, Revista de Política Internacional (69), 3-27.

, 1974a: «Autorité politique et conduite économique», Économies et sociétés. Cahiers de l'I.S.E.A. (1-2): 207-247.

, 1980a: «Freund, devant l'ennemi», Valeurs actuelles (22.XII.1980): 33.

, 1980b: «Le thème de la peur chez Hobbes», Revue européenne des sciences sociales (49): 15-32.

, 1981: «Ébauche d'une autobiographie intellectuelle», Revue européenne des sciences sociales (54-55): 7-47.

, 1983: Sociologie du conflit. París: P.U.F.

, 1985a: «Raymond Aron, directeur de thèse», Commentaire (28-29): 55-58.

, 1985b: «La peur de la peur», Actions et recherches sociales (4): 11-29.

, 1987: «Ricerca sulla pace e ricerca sulla guerra», Behemoth (III:1-2): 49-55.

, 1991: L'aventure du politique: entretiens avec Charles Blanchet. París: Criterion.

, 1993: L'essence de l'économique. Strasbourg: Presses Universitaires de Strasbourg.

, 2004: L'essence du politique. París: Dalloz [1ª ed.: 1965]

GIRALDO RAMÍREZ, J. 1999: «Los otros, que no son el enemigo. Situación polémica y terceros en Schmitt, Freund y Bobbio», Estudios Políticos (14): 135148.

HOLEINDRE, J.-V. 2007: «Penser la ruse avec Julien Freund», en M. Klinger (dir.): Héritage et actualité de la polémologie. París: Tétraèdre, pp. 55-67.

, 2011: «De la guerre au conflit. Sur l'œuvre polémologique de Julien Freund», en G. Delannoi (et alii): Julien Freund, la dynamique des conflits. Berg International, pp. 54-64.

MAFFESOLI, M., \& PESSIN, A. 1978: La violence fondatrice. París: Eds. du Champ Urbain.

MAFFESOLI, M. 2005: La tajada del diablo, compendio de subversión. México D.F.: Siglo XXI.

MOLINA CANO, J. 2000a: Julien Freund, lo politico y la política. Sequitur: Madrid. , 2000b: «Conflicto, política y polemología en el pensamiento de Julien Freund», Barataria (2-3): 117-217. 
, 2004: La politica social en la Historia. Murcia: Isabor.

, 2007: Epitome de la Política social. Murcia: Isabor.

PORTINARO, P. 1992: «Sociologia del conflitto e teoria del politico», en G. Miglio (et al.): Amicus (inimicus) hostis. Le radici concettuali della conflittualità 'privata' e della conflittualità 'politica'. Milano: Giuffrè, pp. 275-310.

SARTORI, G. 1995: Elementi di Teoria Politica. Bologna: Il Mulino.

SAVÈS, C. 1996: «Diritto e politica secondo Julien Freund: elogio del rigore dialettico». Studi Perugini (1): 75-84.

SCHMITT, C. 2002: El concepto de lo político. Madrid: Alianza.

TOMMISSEN 1978: «Contributions de Carl Schmitt à la polémologie», Revue européenne des sciences sociales (44): 141-170.

, 2004: «Julien Freund y Carl Schmitt. Algunos elementos para una reconstrucción de su amistad», Empresas Politicas (5): 117-124.

VALDERRAMA ABENZA, Juan C. 2006: Julien Freund, la imperiosa obligación de lo real. Murcia: Isabor.

,2014: «Julien Freund, analista político: contextos y perspectivas de interpretación», en P. Sánchez Garrido (ed.): Miradas liberales. Análisis político en la Europa del siglo XX. Madrid: Biblioteca Nueva, pp. 99-127.

, 2015: «El enemigo en el orden del espacio. Sobre la condición moral de la enemistad política», en E. Anrubia (ed.): Felicidad y conflicto. Granada: Comares.

, 2017: «Entre clasicismo y modernidad. Sobre el sentido del realismo político en la obra de J. Freund», en J. C. Corbetta \& S. Piana (eds.), El realismo político. Materiales para su estudio. Buenos Aires, Prometeo Editorial [en prensa].

Juan Carlos Valderrama Abenza es Profesor adjunto de Historia de las Ideas y de las Formas Políticas en la Universidad CEU Cardenal Herrera (Valencia). Dpto. de Ciencia Política, Ética y Sociología. Facultad de Derecho, Empresa y Ciencias Políticas.

Líneas de Investigación:

Historia del Pensamiento Político, realismo político y confluencias entre religión y política. Influencia del pensamiento social cristiano y DSI en la constitución histórico-sistemática de la política social contemporánea

Publicaciones recientes:

(2016): Edición, estudio introductorio, epílogo y notas de A. Perpiñá Rodríguez, La época de lo social y otros escritos sobre Política y Seguridad Social. Murcia: Isabor.

(2015): «El enemigo en el orden del espacio. Sobre la condición moral de la enemistad política», en E. ANRUBIA \& Á. DE RUEDA (eds.), Felicidad y conflicto. 
Filosofías para el mundo de mañana, Granada: Comares, pp. 105-119.

Correo electrónico: jvalabe@uchceu.es 